\title{
Goal Optimization for Electricity Management
}

\author{
Neeta Jain, Dr. Sanjay Jain, Dr. Ritu Khanna
}

\begin{abstract}
Goal optimization is the extension of linear programming model which is capable of handling simultaneously many goals which are usually conflicting in nature. Ignizio defined Goal optimization as "It is a tool that has been proposed as a model and approach for analysis of problems involving multiple conflicting objectives". Here in this paper author try to manage Electricity management in household and in industrial sectors. Different models and methods have been adapted for this purpose and finally the proposed method (FAHP) has been presented. The goal programming model has been used to determine the optimal value in Megawatt Hours (MWh) for all energy sources and optimal energy portfolio model is suggested for both economic and ecological sustainability.
\end{abstract}

Index Terms - Goal programming, optimization techniques, Analytic Hierarchy Process (AHP).

\section{INTRODUCTION}

Energy is main factors which effects the growth of any country. It plays important role in determination of policies of government. It is very important for any country to produce their own power so that they are not depended on external resources. Mehmet suggested mixed integer linear programming model which optimized the five goals namely increment in power plants, increase in power generation, decrease in greenhouse gases, increase in installed capacity, and decrease in power consumption. The model was studied for considering renewable power plants and fossil fuels have large share and tried to minimize the deviation of targeted values. They used ranking approach given by Liou and wang for determining priorities.

Renewable energy decision-making can be viewed as a multiple criteria decision-making (MCDM) problem. It includes:

1) Renewable energy planning and policy, referring to the assessment of a feasible energy plan and the diffusion of different renewable energy option;

2) Evaluation and assessment, referring to the assessment of different alternative energies or energy technologies;

3) Technology and project selection, including the site selection, technology selection, and decision support in renewable energy harnessing projects;

4) Environmental, concerned with alternative technologies from an environmental perspective and climate issues; and

5) Operational, referring to the optimal distributed generation outputs to satisfy all the criteria and constraints imposed by the distribution network.

Neeta Jain, Research Scholar, Pacific University, Udaipur

Dr. Sanjay Jain, Associate professor, Department of Mathematical Xcience, S.P.C Government college, Ajmer

Dr. Ritu Khanna, Professor, Department of Basic Science, Faculty of Engineering, Pacific University, Udaipur
The original AHP was developed by Saaty in the late 1970s [15]. In this method, human judgments are represented as crisp values. However, in many practical cases the human preference model is uncertain and decision makers cannot assign crisp values to comparison judgments. In these cases it is useful to implement the fuzzy AHP method. The fuzzy AHP method is designed to improve decision support for uncertain valuations and priorities. The methodology presented in this paper uses data and preferences of experts evaluated under a fuzzy set environment [16]. The use of fuzzy set theory allows the decision makers to incorporate unquantifiable information, incomplete information, non obtainable information, and partially ignorant information into decision model [17].

\section{METHODOLOGY:}

Deviations: The amount away from the desired standards or objectives:

Over achievement $\left(\mathrm{d}^{+}{ }_{i} \geq 0\right)$ vs. Underachievement $\left(\mathrm{d}_{\mathrm{i}}^{-} \geq 0\right)$

Desirable vs. Undesirable Deviations: (depend on the objectives)

$-\mathrm{d}_{\mathrm{i}}^{+}$desirable.

-

Max goals $(\geq)$ - the more the better

$\mathrm{d}_{\mathrm{i}}^{-}$desirable.

both $\mathrm{d}^{+}{ }_{\mathrm{i}}$ and $\mathrm{d}_{\mathrm{i}}^{-}$undesirable

Min goals $(\leq)$ - the less the better -

In GP, the objective is to minimize the (weighted) sum of undesirable deviations (all undesirable $\mathrm{d}^{+}{ }_{i}$ and $\mathrm{d}_{\mathrm{i}} \rightarrow \rightarrow 0$ ).

For each goal, at least, one of $\mathrm{d}^{+}{ }_{\mathrm{i}}$ and $\mathrm{d}_{\mathrm{i}}{ }_{\mathrm{i}}$ must be equal to "0"

A general fuzzy model can be stated as:

$Z_{k}(X) \geq g_{k}$

$Z_{k} \leq g_{k}$

$Z_{k} \cong g_{k}$

Where $g_{k}$ represent the $\mathrm{k}$ goal and $\mathrm{X}=\left(x_{1}, x_{2} \ldots \ldots x_{n}\right)$

$\sum_{i=1}^{\text {s.t }} a_{i j} x_{j} \leq b_{j}$

The greater than, less than or equal to fuggy relation can be found as follows:

The right sided linear function when positive deviation are penalized is given by

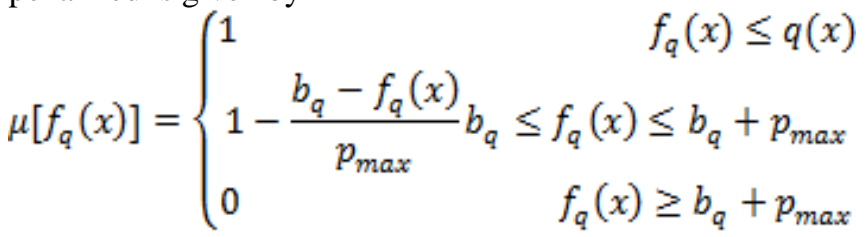




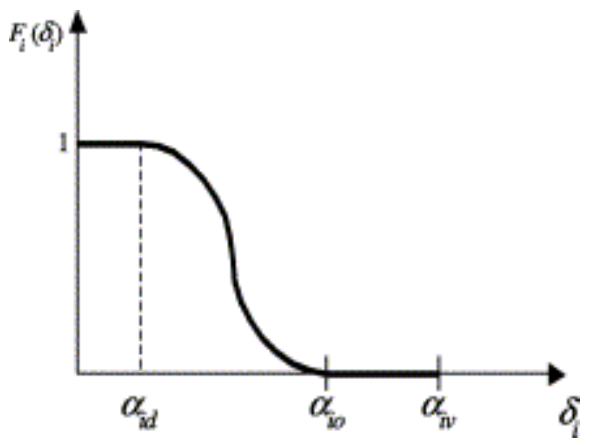

The left side negative deviation penalized linear function

$\mu\left[f_{q}(x)\right]=\left\{\begin{array}{lr}1 & f_{q}(x) \geq q(x) \\ 1-\frac{b_{q}-f_{q}(x)}{n_{\max }} b_{q}- & n_{\max } \leq f_{q}(x) \leq b_{q} \\ 0 & f_{q}(x) \leq b_{q}-n_{\max }\end{array}\right.$

\section{FuZZY ANALYTIC HIERARCHY PROCESS METHOD For OPTIMIZATION OF ELECTRICITY}

The analytic hierarchy process (AHP) can be one of the most widely used multi criteria decision making (MCDM) method. Since a systematic and logical approach is to be used to reach the solution. So the fuzzy set theory might be the most common method in dealing with this objective. Fuzzy analytic Hierarchy process was applied for priorities investment planning of renewable plants. Different power plants were studied under the criteria based on emission of hazardous gases, environmental damages, cost of plant, space requirement and employments. Energy is one of the important key factors in development of humans and it also plays a very important role in development of any country. For any country to develop economically or socially energy (power) plays a key role. Energy is one very basic requirement for the progress of any country. There is increase in demand for energy in a developing nation. The non-renewable sources are depleting and it will become impossible to sustain the every going demand with these resources. The use of renewable energy has witnessed a rapid increase .In India solar power use has increased. In year 2015-16 the solar capacity was 6.76GW which has increased to $5.52 \mathrm{Gw}$ in 2018-2019. Due to this the cost of production has decreased. It becomes very important to make sustainable energy polices keeping social economic and environmental factors in consideration. For production of power local and easily available resources, environmental friendly, sustainable resources are required and their optimal distribution becomes important. The price of fossil fuels are increasing day by day and depleting day by day so it becomes important to search of different resources for production of energy which are more feasible. Many studies have been carried out for allocation of resources for the production of energy. But usually it usually consider single objective like maximization or minimization .But diversity in availability of resources and with social responsibility it become important to use multi objective optimization technique. Energy production should be managed such that wide variety of goals is satisfied all together.

Whatever method you opt for electricity production, at some point of time there is a carbon foot print present. Even with low carbon techniques how large the $\mathrm{CO}_{2}$ is permissible as at the point of installing some greenhouse gases are emitted. Emission of gases can be directly or indirectly present Therefore it become very important to calculated the cycle of $\mathrm{CO}_{2}$ throughout the life cycle of the system

Goal programming is one of the methods which can provide understanding or one can say it can help in solution of multiple objectives simultaneously. Goal programming help in providing solution to policy maker which will be satisfies multiple objective which are often competing for an socio economic environment. There is increasing demand of sustainable development.

The objective of any policy maker is to explore the different technology options with goals like annual cost, carbon emission levels, other air pollutants, fulfillment of requirement of and employment benefits.

The goal programming model is prepared to maximize the power production with various sources, while minimizing $\mathrm{CO} 2$ emissions, Minimize the production cost for different power production plants. The selection of an optimal energy production is faced with multiple alternatives and multiple criteria between now and 2030 .

Cost per unit of electricity: The cost of production of energy depends on various factors, the important being the resources used for production and the availability of resource. The unit energy cost is much higher in photovoltaic as compared to nuclear resources .The production cost per unit using coal, wind and geothermal are very less

$$
\begin{aligned}
& \text { Genric goal programming structure } \\
& \text { Minimize } \left.\mathrm{Z}=p_{1(} d_{1}^{+}+d_{1}^{-}\right) \ldots \ldots \ldots P_{n}\left(d_{n}^{+}+d_{n}^{-}\right) \\
& \text {St: } \\
& a_{11} x_{1}+a_{12} x_{2} \ldots \ldots a_{1 n} x_{n}+p_{1}^{-}-p_{1}^{+}=a_{1} \ldots \ldots . . \\
& \text {.... } \\
& a_{m 1} x_{1}+\cdots \ldots \ldots \quad a_{m n} x_{n}+p_{n}^{+}-p_{n}^{-}=a_{n}
\end{aligned}
$$

Where $x_{j}, d_{i}^{+}, d_{i}^{-} \geq 0$

Goal programming consist of an objective function and a series of goals constraints. The objective function is set to minimize the deviation with the set of goals.

\section{Fuzzy AHP method:}

The fuzzy AHP method involves the following steps:

Step 1. The overall goal (objective) is identified and clearly defined;

Step 2. The criteria, sub criteria, and alternatives are identified;

Step 3. The hierarchical structure is formed;

Step 4. Pairwise comparison is made using Saaty's fuzzified evaluation scale;

Step 5. The priority weighting vectors are evaluated using the row geometric mean method (RGMM);

Step 6. Consistency of the judgments is checked by the geometric consistency index (GCI);

Step 7. The defuzzification and the final ranking of alternatives are defined.

The seven-step algorithm o

\section{Mathematical model for power production:}

Climate change is becoming a very important concern for every country. A number of goal have arises because of this and it can be converted to objective and constraints. The main 
important goal of each nation is to reduce emission of carbon-dioxide and other green house gases .Other important concern is emission of pollutants like nitrogen oxides .The country are struggling to reduce the emissions of these pollutants .on other hand due to deficiency in available resources and insufficient budgets available for investment in new technology, it become difficult to effectively address climate change condition. Due to concentration on reducing emission and addressing climate change, there is negative impact on the growth of nation in terms of growth and overall economic conditions. There it becomes important to create the balance in growth of the nation and climate condition, available resources, time jobs and national policies.

This indicator is measured by the kilograms of $\mathrm{CO} 2$ emission per produced kilowatt-hour of electrical energy. The impact of renewable sources is taken as the reduction of the emission produced by the conventional energy source.

The Total voltage deviation is calculated by:

$$
V_{D}=\sqrt{\sum_{k=1}^{N B}\left(V_{k}-V_{\text {ref }}\right)^{2}},
$$

Where $V_{k}$ is the magnitude of voltage at bus $k, V_{\text {ref }}$ is the magnitude of the slack bus voltage, and $N B$ is the total number of nodes in the network.

The active power losses are calculated as:

$$
\mathrm{P}_{\text {loss }} \sum_{j=1}^{N L} i_{j}^{2} R_{j}
$$

where $R j$ and $i_{j}$ are resistance and actual current of the $j^{\text {th }}$ line, respectively, and $N L$ is the total number of lines.

Net present value (NPV) is used to determine the present value of an investment by the discounted sum of all cash flows received from the project. The formula for the discounted sum of all cash flows can be rewritten as:

$$
\mathrm{N} P V=\sum_{i=1}^{n} C_{i}(1+D)^{i}-C_{0}
$$

where $C_{0}$ is initial investment, $C_{i}$ is cash flow, $d$ is discount rate, and $n$ is time period.

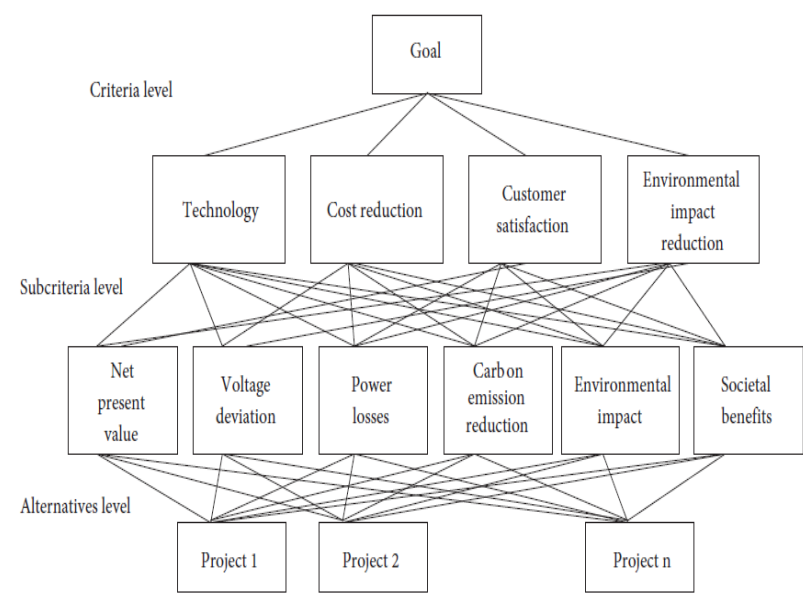

Figure: 1 Hierarchical levels and interdependencies of criteria, sub criteria, and alternatives.

\section{CONCLUSION:}

The new approach in the assessment of renewable energy projects efficiency is to evaluate to what extent these projects are contributing to progress toward the "ideal electricity management" and its expected outcomes (e.g., sustainability, efficiency, consumer inclusion). In this paper, the fuzzy AHP method is used to improve results support for uncertain valuations and priorities. Based on fuzzy matching of alternatives, the methodology proposed in this paper determines the optimal allocation of renewable energy resources.

The proposed methodology is illustrated on the choice of the optimal size, location, and technology of renewable resources planned for integration in the existing distribution network. Author proved that the method is highly successful in the evaluation of alternatives in the presence of heterogeneous criteria. This method allows decision makers to incorporate unquantifiable information, incomplete information, non obtainable information, and partially ignorant information into the decision model.

\section{REFERENCES:}

[1] Afgan NH, Carvalho MG. Multi-criteria assessment of new and renewable energy power plants. Energy 2002; 27:739\{755.

[2] Hosseini SA, Madahi SSK, Razavi F, Karami M, Ghadimi AA. Optimal sizing and siting distributed generation

resources using a multi objective algorithm. Turk J Electr Eng Co 2013; 21 $825\{850$.

[3] Aras H, Erdo_gmu_s S_, Ko_c E. Multi-criteria selection for a wind observation station location using analytic hierarchyprocess. Renew Energ 2004; 29: 1383\{1392.

[4] H. L. LI ,An Efficient Method for Solving Linear Goal Programming Problems, Journal Of Optimization Theory And Aspplications: Vol. 90, No. 2, Pp. 465-469, August 1996

[5] HOLZMAN, A.G. 1981. Mathematical Programming for operations research and computer scientists. New York and Basel: Marcel Dekker, inc. 373 p.

[6] Hurwicz, M.-L. and Rose, M. (2016) Older Adults' Explanatory Models of High Blood Pressure. Health , 8, 680-693

[7] Ignizio J.P. and Perlis, J.H. (1979) Sequential Linear Goal Programming: Implementation via MPSX. Computers and Operations Research, 6, 141-145.

[8] Ignizio, J. P. (1967) A FORTRAN Code for Multiple Objective I.P. North American Aviation Internal Memorandum. [28] Huss, P. (1967) Telephone Communications of January.

[9] Ignizio, J.P. (1966) Adaptive Antenna Array Study. Boeing Company, RWA-5557

[10] Ignizio, J.P. (1976) Goal Programming and Extensions. D. C. Heath and Company, Lexington

[11] Ignizio, J.P. (1985) An Algorithm for Solving the Linear Goal-Programming Problem by Solving Its Dual. Journal of operational Research Society, 36, 507-5 15

[12] J.C. Papageorgiou A Goal Programming Model For Resource Allocation In The School System Of Greece The School System Of Greece", Kybernetes, Vol. 7 Issue: 3, Pp.229-237

[13] JE Hotvedt - Journal of Agricultural and Applied Economics, 1983 cambridge.org Application of linear goal programming to forest harvest scheduling.

[14] Jafari, H., Koshteli, R. and Khabiri, B. (2008) An Optimal Model using Goal Programming for Rice Farm. AppliedMathematical Sciences, 2, 1131-1136.

[15] Saaty TL. The Analytic Hierarchy Process. New York, NY, USA McGraw-Hill, 1980.

[16] Duru O, Bulut E, Yoshida S. Regime switching fuzzy AHP model for choice-varying priorities problem and expert consistency prioritization: a cubic fuzzy-priority matrix design. Expert Syst Appl 2012; 39: 4954\{4964.

[17] Kulak O, Durmusoglu B, Kahraman C. Fuzzy multi-attribute equipment selection based on information axiom. J Mater Process Tech 2005 169: $337\{345$.

[18] Van Laarhoven PJM, Pedrycz W. A fuzzy extension of Saaty's priority theory. Fuzzy Set Syst 1983; 11: 229\{241.

[19] Buckley J. Fuzzy hierarchical analysis. Fuzzy Set Syst 1985; 17 : $233\{247$.

[20] Fatti L. Water research planning in South Africa. In: Golden BL, Wasil EA, Harker PT, editors. The Analytic Hierarchy Process. Berlin, Germany: Springer, 1989; pp. 122\{137. 